\title{
TREATMENT OF POSTPAROTIDECTOMY FISTULAE WITH FIBRIN GLUE
}

\author{
Sander Zwaveling ${ }^{1}$, Pascal Steenvoorde ${ }^{1,2}$, Stephen Andrew da Costa ${ }^{1}$
}

Rijnland Hospital, Netherlands: Department of Surgery¹; Leiden University Medical Center, Netherlands: Department of Surgery ${ }^{2}$

Summary: Although fistulae resulting from superficial parotidectomy represent a serious problem, there is still little consensus on the optimal treatment. Some suggest management by applying dressings, while others advise surgery. In recent years several other strategies have been proposed. In this manuscript, we present two cases of postparotidectomy fistulae treated by injection with fibrin tissue glue (Tissucol ${ }^{\circledR}$ Duo 500, Baxter AG, Vienna, Austria). Furthermore, a review of the literature is presented. In both patients the fistulae completely healed within months without complications. A literature search revealed that this is the first time postparotidectomy fistulae were treated this way. We conclude that postparotidectomy fistulae can be effectively treated with fibrin glue. Moreover, this treatment is simple, safe and has no side effects.

Key words: Postparotidectomy; Fistulae; Treatment; Fibrin; Glue

\section{Introduction}

Numerous methods of managing parotid fistulae have been described in recent years. These include various types of surgery $(1,3,4)$, tympanic neurectomy $(5)$, a conservative approach by applying dressings (16) or administering no food orally until healing occurs (11), the use of botulinum toxin $(7,8,15)$, glycopyrrolate (2), octreotide (13) or injection of a solution of lipiodol with cyanoacrylate (9). Up till now, none of these treatments proved to have a clear advantage over the others.

Here we present, to our knowledge for the first time, the management of two cases of postparotidectomy fistulae using fibrin glue (Tissucol $^{\circledR}$ Duo 500, Baxter AG, Vienna, Austria).

\section{Case reports}

\section{Patient A}

In 1994 a chronically inflamed epidermal cyst behind the left ear lobe was removed in a then 52-year-old man. The lesion already persisted for many years, albeit smaller in size, and had been incised before in another hospital. Due to the chronic character, the decision was made to extirpate the lesion. Intraoperative findings suggested that the cyst spread via the parotic gland. Although there were no immediate postoperative problems, after some months the inflammation reappeared. An additional fistulogram showed a blind ending 2-cm long fistula. The ongoing inflammation eventually led to a superficial parotidectomy in 1996.
Unfortunately the fistula reappeared again and another attempt was made to remove it radically in 1998. The fistula was excised and the wound was primary closed. Due to a series of major vascular operations the fistula related problems moved to the background for the next few years. However, in 2003 the patient addressed our outpatient clinic again. He mentioned loss of saliva through three holes behind the left ear lobe, particularly when eating candy. Again a sialogram was made which depicted a 2-cm long fistula ending blindly. No connection with deeper structures was shown. Since surgery obviously failed to adequately heal the fistula we performed a literature search. Positive reports on the use of fibrin glue in anal fistula drew our attention and we decided to use Tissucol on our patient. The area of the fistula opening was disinfected using alcohol $70 \%$ and sterile drapes were placed. The glue was prepared according to the manufacturers' instructions. A flexible catheter was introduced into the fistula tract as deeply as possible without resistance and then slowly withdrawn while injecting one to two milliliters of glue. Already one week after injection the leakage of saliva had diminished considerably while the inflammation had decreased. After a final control eight weeks later the patient was discharged and over the last two years no further problems have arisen.

\section{Patient B}

In 2001 a then 71-one-year old mentally retarded woman was seen in our outpatient clinic. Her family physician had noted a swelling in her left cheek and she was sent to our hospital. Upon presentation we saw a 4-cm large pre- 
auricular tumor which could not be palpated via the mouth. Additional ultrasound revealed a solid lesion with a $2.3-\mathrm{cm}$ diameter. A biopsy showed a pleomorphic adenoma. Subsequently a superficial and partly deep parotidectomy was performed. During this operation it was necessary to sacrifice some branches of the facial nerve. As a result, the patient postoperatively suffered from paralysis of the ocular and mandibular branches. Moreover, she developed parotiditis some months later, which fortunately responded well to antibiotics. Nonetheless a fluid-producing fistula occurred. A sialogram was made showing a fistula that was connected to a small pocket in the deep lobe of the parotic gland. Encouraged by our previous success with patient A we decided injecting fibrin glue in the fistula. Within weeks the fistula dried up and the inflammation decreased. A second injection followed a few months later in order to stimulate the healing process and since then the fistula completely disappeared.

\section{Discussion}

Postparotidectomy fistulae represent a major complication in parotic surgery with an prevalence of up to $14 \%$ (16). Since many years physicians have tried to avoid and heal postparotidectomy fistulae through various ways. Some authors recommend applying dressings (16) with the disadvantage that patients have to maintain these dressings for several days. Others prefer the rather Spartan treatment of administering no food orally until healing occurs (11). Alternatively, there is the possibility of surgical intervention $(1,3,4)$ such as parotidectomy or tympanic neurectomy (5). Obviously, this carries the risk of infection and damage to the facial nerve.

In more recent years attention has focussed on treatment with chemicals such as Botulinum toxin $(7,8,15) \mathrm{gly}$ copyrrolate (2) and octreotide (13). The former two agents display an anticholinergic effect, with serious side effects that are well known, including constipation, insomnia, nausea and vomiting. Although glycopyrrolate seems to have fewer side effects than Botulinum toxin because of its inability to cross the blood-brain barrier, it is better to avoid these chemicals if possible. Octreotide was first administered by Spinell e.a. in 1995 (13). Despite the fact that a positive effect on the fistulae was detected it should be noted that the drug has to be administered systemically. Because the exact mechanism of its action is not completely known care should be taken to use octreotide for postparotidectomy fistulae.

A rather different strategy was described by Marcus e.a. (9). They injected a solution of lipiodol and cyanoacrylate tissue adhesive inside the fistulae of several patients. This agent polymerizes on contact with saliva, causing an exothermic reaction and subsequent closure of the fistula. However, patients described discomfort following injection of the chemical, making this procedure less feasible, parti- cularly since repetitive injections were necessary. Nevertheless, the idea of sealing fistulae together is very interesting but instead of using cyanoacrylate it may be advantageous to use fibrin tissue adhesives, because of the different mechanism of action. Cyanoacrylates are synthetic and have been shown to be histotoxic when applied below the dermis and are used most successfully at the level of the epidermis for superficial skin closure $(10,14)$. Fibrin glues on the other hand are naturally occurring substrates that are part of normal endogenous clotting mechanisms and are typically applied below the dermis. They are packaged as two separate components that, when mixed on human tissue, simulate the interaction of the endogenous compounds and form a fibrin clot. For these reasons, we decided to focus on the feasibility of fibrin glue with respect to the management of postparotidectomy fistulae. There are several types of fistulae that have been treated with fibrin glue over the last years, but we did not find any article describing the management of postparotidectomy fistulae using this strategy. Examples of healing fistulae with fibrin tissue sealant include esophagothoracocutaneous fistulae (12) and urinary fistulae (6). Overall the results are promising and complication rates are low, but it must be noticed that no major randomised clinical trials have been undertaken. Nevertheless, treatment with fibrin glue is safe and has no side effects, contrary to the other therapies applied thusfar. In this paper we show that injection of postparotidectomy fistulae with fibrin glue resulted in quick healing. Moreover, in both patients no recurrence of the disease was detected. Therefore, we believe that managing these fistulae with fibrin tissue adhesive requires further study and may well prove to be the treatment of choice.

\section{References}

1. Al-Naqeeb N, Dashti H, Hameed Al-Muhanna A, Behbehani A. Parotid gland tumors: a 15-year experience. J R Coll Surg Edinb 1992;37:89-93.

2. Cavanaugh K, Park A. Postparotidectomy fistula: a different treatment for an old problem. Int J Pediatr Otorhinolaryngol 1999;47:265-8.

3. Danford M. Facial sinus formation secondary to a parotid duct calculus. Br Dent J 1993;175:73-4.

4. Demetriades D. Surgical management of post-traumatic parotid sialoceles and fistulae. Injury 1991;22:183-4.

5. Edussuriya B. Parotid fistulae treated by tympanic neurectomy. Ceylon Med J 1994:39:86-7.

6. Evans LA, Ferguson KH, Foley JP, Rozanski TA, Morey AF. Fibrin sealant for the management of genitourinary injuries, fistulas and surgical complications. J Urol 2003;169:1360-1362.

7. Guntinas-Lichius $\mathrm{O}$, Sittel C. Treatment of postparotidectomy salivary fistula with botulinum toxin. Ann Otol Rhinol Laryngol 2001;110:1162-4.

8. Marchese-Ragona R, De Filippis C, Staffieri A, Tugnoli V, Restivo DA. Parotid gland fistula: treatment with botulinum toxin. Plast Reconstr Surg 2001; 107: 886-7.

9. Marcus AJ, Nasser NA. Case report: the treatment of a chronic parotid cutaneous fistula by the injection of a solution of lipiodol with cyanoacrylate. Clin Radiol 1998;53:616-8.

10. Mobley SR, Hilinski J, Toriumi DM. Surgical tissue adhesives. Facial Plast Surg Clin N Am 2002;10:147-154.

11. Parekh D, Glezerson G, Stewart M, Esser J, Lawson HH. Post-traumatic parotid fistulae and sialoceles. Ann Surg 1989;209:105-11.

12. Solt J, Benko I, Papp Z. Endoscopic closure of esophagothoracocutaneous fistula with collagen plug and fibrin glue. Endoscopy 2001;33:556.

13. Spinell C, Ricci E, Berti P, Miccoli P. Postoperative salivary fistula: therapeutic action of octreotide. Surgery 1995;117:117-8. 
14. Toriumi D, Raslan WF, Friedman M, Tardy ME Jr. Histotoxicity of cyanoacrylate tissue adhesives. Arch Otolaryngol Head Neck Surg 1990;116:546-550.

15. Von Lindern JJ, Niederhagen B, Appel T, Bergé S, Reich RH. New prospects in the treatment of traumatic and postoperative parotid fistulas with type A botulinum toxin. Plast Reconstr Surg 2002;109:2443-5.

16. Wax M, Tarshis L. Post-parotidectomy fistula. J Otolaryngol 1991;20:10-13.

Submitted June 2005

Accepted February 2006.

Sander Zwaveling, $M D, P h D$,

Rijnland Hospital,

Department of Surgery,

Simon Smitweg 1,

2353 GA Leiderdorp,

Netherlands.

e-mail: s.zwaveling@rijnland.nl 